\title{
A Associação Brasileira de Psiquiatria e a Reforma da Assistência Psiquiátrica no Brasil ${ }^{*}$
}

Os diferentes tipos de transtornos mentais acometem uma em cada três pessoas ao longo da vida. Além disto, dados de um estudo realizado em 1990 pela Organização Mundial da Saúde, pela Escola de Saúde Pública da Universidade de Harvard e pelo Banco Mundial, demonstram que entre as dez maiores causas de incapacitações em todo o mundo, cinco são transtornos mentais.

A assistência psiquiátrica impõe-se como técnica, e eticamente necessária, sempre que há um transtorno mental identificado, apresentando à pessoa um quadro clinicamente significativo e acompanhado de sofrimento ou incapacidade.

Sob o ângulo da oferta terapêutica, a assistência psiquiátrica impõe-se também quando existem tratamentos disponíveis e reconhecidamente eficazes no reestabelecimento da capacidade funcional e da estabilidade clínica da pessoa enferma ou, ao menos, capazes de aliviar o sofrimento experimentado por essa pessoa.

Se, de um lado, constitui fato indiscutível que a abordagem médico-psiquiátrica de muitos transtornos mentais ocupa papel fundamental em seu diagnóstico e tratamento, por outro é preciso reconhecer que, tendo em vista a especificidade e a complexidade do processo de adoecimento psíquico, outras modalidades terapêuticas, além daquelas de natureza predominantemente somática, revestem-se de extrema importância para a obtenção de resultados clínicos relevantes e duradouros.

Assim, questões como o trabalho em equipe multiprofissional e interdisciplinar, a pluralidade dos saberes e a complexidade das ações e dos serviços assistenciais passam a dominar o campo acadêmico e profissional como requisitos fundamentais para o processo de reforma da assistência psiquiátrica. Conceitos como desospitalização e desinstitucionalização guiam o processo de mudança de foco dominante das ações em saúde mental da área intra-hospitalar especializada para a extrahospitalar, onde serviços ambulatoriais e centros de atenção diária, todos referidos à comunidade, passam gradativamente a assumir e dividir o papel da assistência em saúde mental.

Nas últimas décadas, importantes mudanças na área dos conhecimentos teóricos em neurociências e dos instrumentos técnicos da medicina em geral e da psiquiatria em particular, além daqueles pertencentes a outros saberes, têm facilitado as transformações no campo das políticas de saúde, favorecendo a reorganização da assistência aos doentes mentais. Neste sentido, por intervenções de natureza diversa, tem sido possível manter pessoas gravemente enfermas por maior tempo em seu meio social, alargar os períodos livres de sintomas e obter maior êxito com procedimentos visando reabilitação.

Tendo em conta o estado ainda vigente particularmente em inúmeros "hospitais psiquiátricos" brasileiros, as questões anteriormente apontadas refletem-se na discussão de políticas de saúde dirigidas à assistência à saúde mental, e em esforços legislativos que venham a dar respaldo legal à transformação das práticas psiquiátricas, à ampliação e proteção dos direitos à saúde e ao respeito à cidadania das pessoas acometidas por transtornos mentais.

É nesse cenário que se deu a apresentação em setembro de 1989 do Projeto de Lei n ${ }^{\circ} 3.657$ do deputado Paulo Delgado e até atualmente se processa sua discussão nas duas casas que compõem o Congresso Nacional, visto que o decreto que ainda rege a atenção aos portadores de transtornos mentais no país data de julho de 1934.

\section{Antecedentes históricos}

A assistência psiquiátrica no Brasil esteve centrada desde o século passado em hospitais com características asilares, ainda que algumas experiências inovadoras isoladas pudessem ser observadas. Até a década de 60, esses hospitais eram quase que exclusivamente estatais ou filantrópicos, mas na década de 70 observou-se uma grande expansão da rede hospitalar psiquiátrica privada.

Ainda nos primórdios dessa expansão, a Comissão de Saúde Mental da Associação Brasileira de Psiquiatria afirmava, em um relatório datado de julho de 1971, que "A ABP entende que é necessária uma mudança de atitude em relação à saúde e à doença mental, mudança que deve começar pelos próprios psiquiatras e outros trabalhadores de saúde mental, que devem reformular seus conceitos sobre o tratamento e a prevenção dos transtornos mentais. (...) a ênfase de nossos esforços deve ser dirigida por uma ação global de saúde mental, com serviços hospitalares e extra-hospitalares, todos eles solidamente ligados à comunidade".

Nessa mesma época, o Professor Luiz Cerqueira da Faculdade de Medicina da USP-Ribeirão Preto já dizia que "A empresa de saúde sempre viu o lucro e só o lucro. Não nos iludamos, porque este é o seu papel... Em psiquiatria, já têm o monopólio da assistência curativa individual através do leito hospitalar exatamente por ser a opção mais rendosa”.

Curiosamente, surgiram algumas iniciativas até mesmo de órgãos do governo que se opunham a essa tendência, mas que

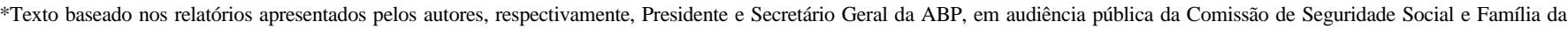
Câmara dos Deputados, Brasília, 19/10/2000. 
não saíam do papel. Assim, a Previdência Social aprovou, em 1973, um Manual de Serviço para Assistência Psiquiátrica que, ainda segundo o Professor Luiz Cerqueira, foi sabotado desde seu primeiro dia. Esse manual já colocava em instâncias extrahospitalares a função de evitar as internações desnecessárias, condenando taxativamente as internações em macro-hospitais e consagrando a equipe multiprofissional.

Quase uma década depois, o então Ministério da Previdência e Assistência Social aprovou, em 1982, um "Plano de Reorientação da Assistência Psiquiátrica Previdenciária", plano que deveria ser implantado de forma gradual e progressiva pelo Inamps. Os princípios específicos da área da saúde mental ali propostos novamente incluíam uma atenção predominantemente extra-hospitalar, a utilização de equipe multiprofissional, a inclusão em estratégia de atenção primária de saúde, a utilização de recursos e métodos intermediários entre o ambulatório e a internação integral, a utilização de internação integral pelo menor prazo possível apenas para aqueles pacientes que representem risco para si ou para terceiros (ou totalmente impossibilitados de ser mantidos em seu meio familiar e social) e, finalmente, a promoção progressiva de pequenas unidades psiquiátricas em hospitais gerais.

Ainda nesse ano de 1982, o então Senador André Franco Montoro assume o Governo do Estado de São Paulo, nomeando João Yunes para a Secretaria de Estado da Saúde e Marcos Pacheco de Toledo Ferraz, recém saído da Presidência da Associação Brasileira de Psiquiatria, para a direção da Coordenadoria de Saúde Mental do Estado. Um censo hospitalar realizado pela coordenadoria, também em 1982, veio a demonstrar que $70 \%$ das pessoas abrigadas em hospitais psiquiátricos públicos e privados estavam ali confinadas há mais de um ano, e mais de $40 \%$ pareciam absolutamente segregadas da família e da sociedade por mais de cinco anos. Por ocasião de uma crise no Hospital do Juqueri no ano seguinte, denunciava Marcos Ferraz: "Se o Juqueri representa a crise, é preciso refletir sobre a hipocrisia social que se horroriza com ela. O fenômeno Juqueri nada mais é do que o reflexo da exclusão que a mesma sociedade faz de seus segmentos mais marginalizados nas periferias, nas favelas, nos cortiços, no desemprego ou no subemprego." Durante todo o Governo Montoro, as ações da Coordenadoria de Saúde Mental visavam o que se denominou "a inversão de uma tendência perversa", qual seja, a tentativa de desmantelamento de um sistema hospitalocêntrico.

No final da década de 80 e início da década de 90, uma série de diferentes iniciativas e documentos clamam por um respeito aos direitos dos pacientes psiquiátricos, que devem ter reconhecida sua cidadania, e por mudanças na legislação que regula a assistência psiquiátrica, particularmente no que concerne ao modelo hospitalocêntrico vigente e à questão das internações involuntárias. São de 1989 a Declaração de Luxor sobre os Direitos Humanos dos Doentes Mentais, da Federação Mundial para Saúde Mental e, no Brasil, o Projeto de Lei do deputado Paulo Delgado. Em 1990, surge a Declaração de Caracas, documento final da Conferência Regional para a
Reestruturação da Atenção Psiquiátrica na América Latina no Contexto dos Sistemas Locais de Saúde, convocada pela Organização Pan-americana da Saúde. Finalmente, nesse mesmo período, a Assembléia Geral da Organização das Nações Unidas adota, em dezembro de 1991, os Princípios para a Proteção dos Enfermos Mentais e para a Melhoria da Atenção à Saúde Mental.

A tônica desse documento diz respeito aos direitos dos pacientes psiquiátricos e inclui, entre outros princípios, os concernentes a suas liberdades fundamentais e direitos básicos, como o direito de viver na medida do possível na comunidade; o direito à confidenciabilidade, às normas de atenção e a ser tratado em um ambiente o menos restritivo possível; e o direito de acesso à informação relativa a si mesmo, de consentimento para o tratamento (ou, na sua impossibilidade, dos procedimentos necessários para que tratamento necessário ou admissão involuntária possam ser adotados) e de condições adequadas nas instituições psiquiátricas. Esses princípios foram discutidos em sessão plenária, realizada em junho de 1994, do Conselho Federal de Medicina, visando sua adoção na forma de uma resolução do referido órgão normatizador da atividade médica no Brasil quando era presidido por Ivan Moura Fé.

Durante o início dos anos 90, deputados do Partido dos Trabalhadores vieram a propor projetos de lei em diversos estados brasileiros. Entretanto, muitos desses projetos de lei estadual iam além do proposto em nível federal pelo deputado Paulo Delgado, propondo, além do "fechamento dos manicômios", diretrizes terapêuticas que chegavam a proibir a utilização de eletroconvulsoterapia em quaisquer circunstâncias e medidas restritivas ao próprio desenvolvimento de pesquisas científicas.

Em junho de 1995, um boletim informativo da Organização Pan-americana da Saúde faz um balanço geral da situação na América Latina: “(...) relativamente poucos governos adotaram planos nacionais de saúde mental e os que o fizeram não deram apoio suficiente aos mesmos. (...) os serviços de saúde (...) continuam girando em torno dos hospitais psiquiátricos (...) A sociedade, em sua maioria, continua estigmatizando e isolando as pessoas acometidas de doenças mentais, com o que não consegue outra coisa senão perpetuar o problema".

Em novembro de 1999, os delegados de diversos países latinoamericanos, reunidos em Assembléia da Associação Psiquiátrica da América Latina (Apal) - instituição também signatária da Declaração de Caracas -, na Ilha de Margarida, Venezuela, aprovaram um documento pelo qual manifestavam sua preocupação com o que se observava na região e faziam recomendações aos governos dos países latino-americanos. A Declaração de Margarida, da qual a Associação Brasileira de Psiquiatria é signatária como entidade membro da Apal, reafirma os propósitos de "terminar definitivamente com as instituições manicomiais", porém aponta que alguns governos latinoamericanos "se limitam ao fechamento das instituições com o propósito de reduzir os investimentos em saúde mental, lançando às ruas pessoas com sofrimento mental para as quais não se criaram as redes assistenciais necessárias, nem as condições comunitárias que facilitem sua reinserção social". 
As recomendações da Apal aos governos latino-americanos na Declaração de Margarida destacam a “(...) reorientação dos programas de saúde mental e de psiquiatria para a atenção primária (...) mantendo a existência de hospitais especializados devidamente transformados em sua concepção, infra-estrutura e recursos humanos (...) integrados à rede assistencial e comunitária (...) criar estruturas intermediárias de trânsito até a plena reinserção social”.

\section{A posição da ABP}

Quando da apresentação do Projeto de Lei pelo deputado Paulo Delgado em 1989, a Associação Brasileira de Psiquiatria participava de um grupo de trabalho da Divisão Nacional de Saúde Mental do Ministério da Saúde que discutia a modernização da legislação psiquiátrica no país. Essa associação considerou que o projeto de lei apresentado correspondia em linhas gerais aos seus anseios, tendo aprovado uma moção de apoio ao mesmo em congresso realizado em São Paulo ainda naquele ano. Posteriormente, a ABP veio a participar ativamente das discussões que o mesmo suscitou em diversos níveis, inclusive no Senado Federal (onde compareceram Ullysses Vianna Filho e Marcos Pacheco de Toledo Ferraz, dois expresidentes da associação). Naquela ocasião, por esses dois lídimos representantes, a Associação Brasileira de Psiquiatria mais uma vez manifestou opinião favorável ao projeto de lei, embora criticasse a proposição de "extinção progressiva dos manicômios", se esse termo estivesse ali como sinônimo de hospital psiquiátrico.

A Assembléia de Delegados, órgão máximo da Associação Brasileira de Psiquiatria, reunida em outubro de 1999 em Fortaleza, aprovou por unanimidade uma posição oficial da entidade que apóia todo e qualquer movimento que defenda os direitos de cidadania das pessoas acometidas por transtornos psiquiátricos, bem como considera essencial a atuação médico-psiquiátrica no tratamento, na readaptação e nos processos de ressocialização dessas pessoas. O que essa associação defende é que se garanta aos pacientes não somente seus direitos básicos de cidadãos, como também, e principalmente, o direito de ser alvo de atenção profissional de qualidade e poder usufruir dos melhores recursos diagnósticos e terapêuticos disponibilizados pelo progresso da ciência, além de uma necessária normatização das internações involuntárias e compulsórias.

Entendemos que a imensa maioria dos "hospitais psiquiátricos" brasileiros mereçam ser fechados, pois sequer poderiam ser denominados de hospitais. Muitos deles constituem apenas um depósito desumanizado de pacientes, funcionando como elemento intensificador de doenças, pois não é possível denominar-se tratamento a uma consulta semanal de poucos minutos. Não consideremos essa prática, entretanto, como sinônimo de internação hospitalar. A despeito do progresso observado nos meios diagnósticos e terapêuticos à disposição dos psiquiatras e de outros profissionais da saúde mental, e mesmo contando com adequada rede de serviços assistenciais extra-hospitalares (o que ainda não ocorre em nosso país), hospitais psiquiátricos de qualidade têm um papel a cumprir dentre os recursos com os quais devemos contar para a proteção de alguns de nossos pacientes.

Situações clínicas que representem risco para o paciente ou para outras pessoas, bem como a instituição de procedimentos terapêuticos que demandam acompanhamento especializado contínuo, implicam necessariamente a internação do paciente como medida protetiva. Essa internação, sempre que possível em serviço próximo ao de moradia do paciente, poderá se dar na dependência de características nosológicas, terapêuticas e mesmo individuais - em enfermarias psiquiátricas de hospitais gerais ou mesmo em hospitais psiquiátricos. Critérios objetivos devem nortear o credenciamento dos serviços psiquiátricos (mesmo extra-hospitalares) considerados de qualidade, bem como a sua distribuição ao longo do território nacional.

Também consideramos oportuno que se delimite conceitualmente os hospitais psiquiátricos dos assim chamados manicômios (em realidade, judiciários) e instituições de caráter asilar. Em relação a estes últimos, há que se proceder a uma avaliação caso a caso de pacientes que, mais por condições sociais que propriamente nosológicas, necessitem permanecer institucionalizados por longos períodos de tempo. Dizia Yves Pelicier que asilo era "um lugar para os sem lugar".

Sempre que a desinstitucionalização for possível - e ela é na maioria das vezes - deve ser feita de forma gradual, assistida e respeitando as vulnerabilidades de cada pessoa. $\mathrm{O}$ que se denominou corretamente de desinstitucionalização não pode representar, como se observou em muitos países, desospitalização com desassistência. Ou, como já se ouviu, "o que está havendo é despejo e não desospitalização".

Outro aspecto importante, e muitas vezes negligenciado, é que a hospitalização ou manutenção desnecessária do paciente internado não são os únicos agentes que tornam crônicas manifestações psicopatológicas. Na realidade, a cronicidade está mais relacionada à ausência de assistência ou à assistência inadequada do que necessariamente ao local onde ela acontece. Encontramos pacientes com quadros psiquiátricos intensificados entre os sem-teto que perambulam desassistidos pelas ruas e mesmo entre pacientes usuários de serviços extrahospitalares nunca internados anteriormente.

Simplesmente fechar as portas dos hospitais, sem antes criar locais de atendimento adequado aos pacientes, com a devida requalificação dos profissionais para esse novo tipo de demanda, joga os pacientes no limbo da falta absoluta de cuidados e viola seu direito mais essencial: acesso ao melhor tratamento disponível para a sua necessidade clínica. Dentro dessa premissa, há espaço para leitos psiquiátricos que representem efetivo avanço no modelo de assistência hospitalar. O que observamos é que não tem interessado à iniciativa privada investir para modernizar seus hospitais psiquiátricos, criar unidades psiquiátricas em hospital geral ou boas estruturas extra-hospitalares substitutivas como hospitais-dia. E uma das razões para isto é que, deixando de oferecer uma assistência massificada e voltando-se para uma atenção mais individualizada, com equipes multiprofissionais qualificadas, esbarra em um custo mais alto do que a simples 
manutenção de macro-hospitais psiquiátricos, custo esse não remunerado adequadamente pelo SUS ou por convênios e planos de saúde privados.

Ressalte-se igualmente a importância de investimento em programas de reabilitação, importante fator de redução de morbidade e das taxas de reinternação, aumentando a qualidade de vida e a autonomia dos pacientes, além de aumentar a adesão ao tratamento. A reabilitação psicossocial amplia os benefícios obtidos pelo tratamento clínico de modo a minimizar os efeitos da incapacidade e das deficiências.

A necessária reforma da assistência psiquiátrica no Brasil não pode ser partidária ou transformada em instrumento de lutas corporativas, para não deixar de atender aos interesses dos pacientes e seus familiares, exatamente os mais penalizados pela situação que originou esse movimento na década de 80 e que, apesar do que se conseguiu até aqui, ainda persiste nos dias de hoje.

Finalmente, no que diz respeito à internação psiquiátrica involuntária, é nosso pensamento que deva ser facultado ao médico - da mesma forma como em outras especialidades adotar procedimento que seu conhecimento técnico e sua experiência recomendem como o mais apropriado, particularmente nas situações em que exista risco para a integridade física do próprio paciente ou de outrem. Uma vez que o paciente tenha sido internado involuntariamente, e se caracterize um conflito de opiniões entre o parecer médico e sua vontade, a legislação deve prever uma instância de arbitramento - em nossa sociedade, usualmente no âmbito judiciário - que possa, com a devida assessoria técnica, decidir quanto à manutenção ou não do paciente internado.

\section{Conclusão}

Em síntese, a Associação Brasileira de Psiquiatria entende que muito se avançou nas discussões concernentes aos conteúdos do Projeto de Lei originalmente proposto pelo deputado Paulo Delgado e de seus substitutivos. A sociedade brasileira como um todo, os psiquiatras e outros profissionais de saúde mental e, particularmente, os pacientes com transtornos psiquiátricos e seus familiares necessitam urgentemente que essa Casa chegue logo a um texto final após mais de dez anos de tramitação do referido projeto de lei no Congresso Nacional.

Deve-se inserir a reforma da assistência psiquiátrica dentro da política de saúde mais geral e também dentro da política econômica do país. Não deve ser justificativa principal a diminuição dos custos com o tratamento. Políticas sociais no Brasil, particularmente na área da saúde e da educação, estão ainda por merecer atenção e investimento adequados para se tornarem disponíveis a todos os segmentos populacionais.

Miguel R Jorge e Josimar MF França Associação Brasileira de Psiquiatria 